\title{
EL GASTO PÚBLICO EN COLOMBIA REFLEXIONES Y PROPUESTAS
}

\author{
Jorge Espitia ${ }^{\mathrm{a}}$ César Ferrari ${ }^{\mathrm{b}}$, Jorge Iván González', Isidro Hernández ${ }^{\mathrm{d}}$ \\ Luis Carlos Reyes, Alejandra Romerof, Carlo Tassara ${ }^{\mathrm{f}}$ \\ David Varela ${ }^{\mathrm{h}}$ Jairo Villabona ${ }^{\mathrm{i}}$, Gustavo Zafra
}

DOI: https://doi.org/10.18601/01245996.v21n40.11. Recepción: 02-09-2018, modificación final: 20-10-2018, aceptación: 30-10-2018. Sugerencia de citación: Espitia, J., Ferrari, C. et al. (2019). El gasto público en Colombia. Reflexiones y propuestas. Revista de Economía Institucional, 21(40), 291-326.

a Profesor de la Escuela Colombia de Ingeniería, Bogotá Colombia, [jeespitia@gmail.com], [https://orcid.org/0000-0002-1632-7580].

b Profesor de la Pontificia Universidad Javeriana, Bogotá, Colombia, [ferrari@javeriana.edu.co], [https://orcid.org/0000-0002-0247-976X].

c Profesor de la Universidad Externado de Colombia, Bogotá, Colombia, [jorgeivangonzalez29@gmail.com],[https://orcid.org/0000-0003-4845-2690]

${ }^{d}$ Profesor de la Universidad Externado de Colombia, Bogotá, Colombia, [isidro.hernandez@uexternado.edu.co], [https://orcid.org/0000-0001-5105-3549].

e Profesor de la Pontificia Universidad Javeriana, Bogotá, Colombia, [luis_ reyes@javeriana.edu.co]. [https://orcid.org/0000-0003-4446-0044].

f Consultora independiente. [jenny.romero@javeriana.edu.co], [https://orcid.org/0000-0002-5356-8375].

g Profesor de la Universidad Externado de Colombia, Bogotá, Colombia, y de la Università degli Studi di Roma “La Sapienza”, Roma, Italia, [tassara@ cisp.ngo.org], [https://orcid.org/0000-0001-7157-9564].

h Profesor de la Pontificia Universidad Javeriana, Bogotá Colombia, [davidfvarelas@gmail.com], [https://orcid.org/0000-0002-9147-9808].

${ }^{i}$ Profesor de la Universidad Nacional de Colombia, Bogotá, Colombia, [jovillabonar@unal.edu.co], [https://orcid.org/0000-0002-4060-7478].

j Profesor de la Pontificia Universidad Javeriana, Bogotá, Colombia, [gzafra@javeriana.edu.co].

Revista de Economía Institucional, vol. 2 I, n. ${ }^{\circ}$ 40, Enero-Junio/20i9, PP. 29 i-326 ISSN OI 24-5996/E-ISSN 2346-2450 


\section{E1 gasto público en Colombia. Reflexiones y propuestas}

Resumen. Los análisis del gasto público en Colombia tienden a concentrarse en aspectos coyunturales y suelen concluir que se debe reducir para garantizar el equilibrio macroeconómico. Este artículo parte del hecho de que la Constitución de 1991 adoptó un Estado de derecho que modernizaría la sociedad colombiana y garantizaría a toda la población el cumplimiento de los derechos económicos y sociales allí consagrados. Desde esa óptica examina los problemas de inequidad, los requerimientos de infraestructura para mejorar el crecimiento económico de largo plazo, y cumplir los Acuerdos de Paz firmados entre el gobierno y las FARC y los compromisos internacionales a que dieron lugar. En contra de los análisis convencionales de corto plazo, para lograr los propósitos mencionados se requiere un mayor gasto público, que se asigne y ejecute de una manera eficiente y equitativa que evite las prácticas corruptas.

Palabras clave: gasto público, crecimiento económico, gasto social, pensiones, subsidios, ingreso básico universal; JEL: F43, H23, H24, H25, H50, H72, H75.

\section{Public spending in Colombia. Reflections and proposals}

Abstract. Analyses of public spending in Colombia tend to concentrate on short-term issues and tend to conclude that it must be reduced to guarantee macroeconomic equilibrium. This article is based on the fact that the 1991 Constitution adopted a Rule of Law that promised to modernize Colombian society and guarantee the fulfillment of economic and social rights for to the entire population. From this point of view, it examines the problems of inequality, the infrastructure requirements to improve long-term economic growth, and to comply with the Peace Agreements and the international commitments to which they gave rise. Contrary to conventional short-term analyses, to achieve the aforementioned purposes, greater public spending is required, which is allocated and executed in an efficient and equitable manner that avoids corrupt practices.

Keywords: public spending, economic growth, social spending, pensions, subsidies, universal basic income; JEL: F43, H23, H24, H25, H50, H72, H75.

\section{Despesa pública na Colômbia. Reflexões e propostas}

Resumo. As análises da despesa pública na Colômbia tendem a se concentrar em aspectos conjunturais e costumam concluir que se deve reduzir para garantir o equilíbrio macroeconômico. Este artigo parte do fato de a Constituição de 1991 ter adotado um Estado de direito que prometeu modernizar a sociedade colombiana e garantir o cumprimento dos direitos econômicos e sociais à população. Dessa perspectiva, examinam-se os problemas de inequidade, os requisitos de infraestrutura para melhorar o crescimento econômico de longo prazo e cumprir com os acordos de paz e com os compromissos internacionais estabelecidos. Em oposição às análises convencionais de curto prazo, para atingir os propósitos mencionados, requer-se maior gasto público, que seja designado e executado, de maneira eficiente e equitativa, a fim de evitar as práticas corruptas.

Palavras-chaves: despesa pública, crescimento econômico, gasto social, pensões, subsídios, renda básica universal; JEL: F43, H23, H24, H25, H50, H72, H75. 
$\mathrm{M}$ ientras que algunas voces reclaman un aumento del gasto público en Colombia para atender las necesidades postergadas, otras piden reducirlo. En los países de la Organización para la Cooperación y el Desarrollo Económico (OCDE), a la que se acaba de ingresar, dicho gasto es de un 40\% a un 50\% del PIB. En los análisis recientes de política pública se utilizan las comparaciones con la OCDE porque permiten conocer la importancia relativa de los ingresos y del gasto En Colombia, según el último Marco Fiscal de Mediano Plazo (Ministerio de Hacienda, 2018), el gasto del gobierno central será del 18,2\% del PIB en 2018, incluida una inversión del 1,7\%. Esta situación es explicable: según este marco fiscal, el recaudo tributario será del 13,6\% y el recaudo total del 15,1\% (ibíd.). En concordancia con ello, propone cumplir la regla fiscal reduciendo el gasto a través de la "austeridad inteligente", minimizando la importancia del cierre fiscal mediante impuestos progresivos.

Para abordar la conveniencia, la dimensión y el alcance del gasto público es necesario saber qué tipo de Estado definió la sociedad y cuán lejos está de establecerlo; así como adelantar un debate público sobre su eficiencia, su eficacia y la mejor manera de administrarlo, entre otras cosas para erradicar la corrupción.

Para contribuir a ese debate y sin más interés que el de ayudar a mejorar las decisiones de política, exponemos una serie de reflexiones y propuestas sobre el gasto fiscal en Colombia y las reformas que se requieren, reflexiones y propuestas que complementan nuestro trabajo sobre la cuestión tributaria (Espitia, Ferrari et al., 2017).

\section{DERECHOS, MERCADOS Y OBLIGACIONES DEL ESTADO}

El tipo de Estado por el que optó el país se definió en la Constitución de 1991, la cual estableció una serie de derechos económicos, sociales y ambientales a los que deberían tener acceso todos los colombianos.

Parte de esos derechos son bienes públicos que, como la seguridad, la justicia y el medio ambiente, no son rivales ni excluyentes. Debido a estas características no son suministrados en forma adecuada y eficiente por los mercados, aunque benefician a todos los ciudadanos. Es por ello que debe proporcionarlos el Estado. Otra parte son bienes meritorios -alimentación, educación, salud y vivienda-, que por satisfacer necesidades básicas son muy apreciados. Los mercados suministran parte de ellos, pero debido a la falta de ingresos una gran proporción de la población no tiene un acceso suficiente, razón por la cual el Estado debería suministrarlos o proporcionar los medios para conseguirlos. 
Por otro lado, si en los mercados respectivos no hay suficiente competencia y funcionan como oligopolios o carteles, las empresas participantes tienden a fijar precios muy altos que les reportan enormes rentas en perjuicio de los consumidores. Por ello, el Estado debe regularlos. Además, debe promover el empleo general de la población, con alta productividad, para que incluso las personas más desprotegidas tengan un ingreso decoroso. Para compensar limitantes estructurales del mercado laboral se ha recurrido a los subsidios, los cuales, aunque sean necesarios y puedan ser efectivos en las circunstancias actuales, no son buenos sustitutos de una política que resuelva la escasez de empleos de alta productividad ${ }^{1}$.

Por otro lado, los bienes y servicios en los que se concretan los derechos económicos y sociales se relacionan con activos requeridos para viabilizar los procesos productivos. Estas inversiones que eventualmente se recuperarían en el largo plazo, no suelen ser atractivas para la inversión privada. Es el caso, por ejemplo, de la infraestructura de transporte, comunicaciones, riego, agua potable y procesamiento de basuras y desechos. En particular, la situación es muy grave en materia de transporte, porque Colombia presenta un significativo atraso frente a los estándares internacionales. No es exagerado afirmar que las vías de segundo y tercer nivel (estimadas en 150 mil km) casi en su totalidad se encuentran en muy mal estado.

Durante los últimos años, los avances en Colombia en cuanto al respeto al derecho a la vida y a la integridad personal han sido sustanciales. Los indicadores muestran una reducción de los homicidios y las lesiones personales, en gran medida debido a la desmovilización de las FARC gracias al Acuerdo de Paz con el gobierno Santos. No obstante estos logros, continúan los enfrentamientos que tienen su origen en la delincuencia alimentada por del narcotráfico, las explotaciones mineras ilegales, el contrabando y las empresas criminales transnacionales. Preocupa además el aumento de los delitos contra la propiedad en las grandes ciudades.

Esta situación tiene que ver, en gran medida, con la incapacidad de la política pública actual para resolver los problemas de inequidad y falta de empleo, así como para superar el prohibicionismo en materia de narcóticos, lo que genera unas rentabilidades elevadísimas y atrae grandes mafias nacionales y transnacionales.

1 Para algunos analistas, incluido Luis Carlos Reyes, coautor de este trabajo, los subsidios condicionados son complementarios de una política económica de pleno empleo que lleve los ingresos a un nivel mínimo aceptable socialmente. Esto es parte del debate sobre la renta básica universal que se trata más adelante.

Revista de Economía Institucional, vol. 2 i, N. ${ }^{\circ}$ 40, enero-junio/20i9, Pp. 29 I-326 ISSN OI 24-5996/E-ISSN 2346-2450 
La necesidad de armonizar el desarrollo económico con la sostenibilidad ambiental implica un mayor esfuerzo de coordinación de los gobiernos nacional y local. Los mecanismos de participación contemplados en la Constitución de 1991 se deben armonizar con una adecuada regulación de las consultas. Es necesario dar mayor seguridad jurídica a todos los actores, y hay una insuficiente regulación de estos mecanismos que afecta su credibilidad y su confiabilidad.

Finalmente, el cumplimiento de los Acuerdos de Paz y de los compromisos internacionales que de ellos se derivan puede asegurarse si se respetan las decisiones de la Corte Constitucional.

Por todas esas consideraciones, la modernización de la sociedad colombiana requiere que el gasto público aumente y que sea más eficiente. Implica también, para el Estado, la sociedad y los agentes públicos y privados, un gran esfuerzo de pedagogía, educación y convencimiento de que la democracia y una sociedad equitativa se ganan día a día y que los derechos no se regalan.

\section{LA DIMENSIÓN DEL GASTO PÚBLICO EN COLOMBIA}

En Colombia el presupuesto de la Nación se descompone en gastos de funcionamiento y gastos de inversión. Los gastos de funcionamiento son los gastos operativos recurrentes del presupuesto. El gasto de inversión incluye la formación bruta de capital que realiza el Estado.

La distinción entre funcionamiento e inversión nunca ha sido suficientemente clara, y casi un 50\% de la inversión incluye gastos de funcionamiento. Afortunadamente, con la entrada en vigor del Decreto 412 de 2018 y la Resolución 10 de 2018 del Ministerio de Hacienda, a partir de 2019 las cifras serán más claras pues las órdenes de servicio (ODS) pasarán a ser compras de servicios y la inversión propiamente dicha a ser adquisición de activos.

Los cuadros 1 y 2 muestran los montos de la ejecución del presupuesto general de la Nación entre 2000 y 2018, en miles de millones de pesos de 2018 y como porcentaje del PIB. El cuadro 3, que muestra la estructura del presupuesto, presenta los tres rubros presupuestales más importantes y sus principales desagregaciones: gastos de funcionamiento, servicio de la deuda e inversión.

$\mathrm{E} 1$ nivel de gasto como porcentaje del $\mathrm{PIB}$ se mantuvo prácticamente estable -alrededor del 24,3\%- entre 2000 y 2018, con pequeñas variaciones en el periodo. Esa es la principal razón de que el gasto público no acompañara en forma suficiente el desarrollo del país ni cumpliera los mandatos de la Constitución de 1991. 


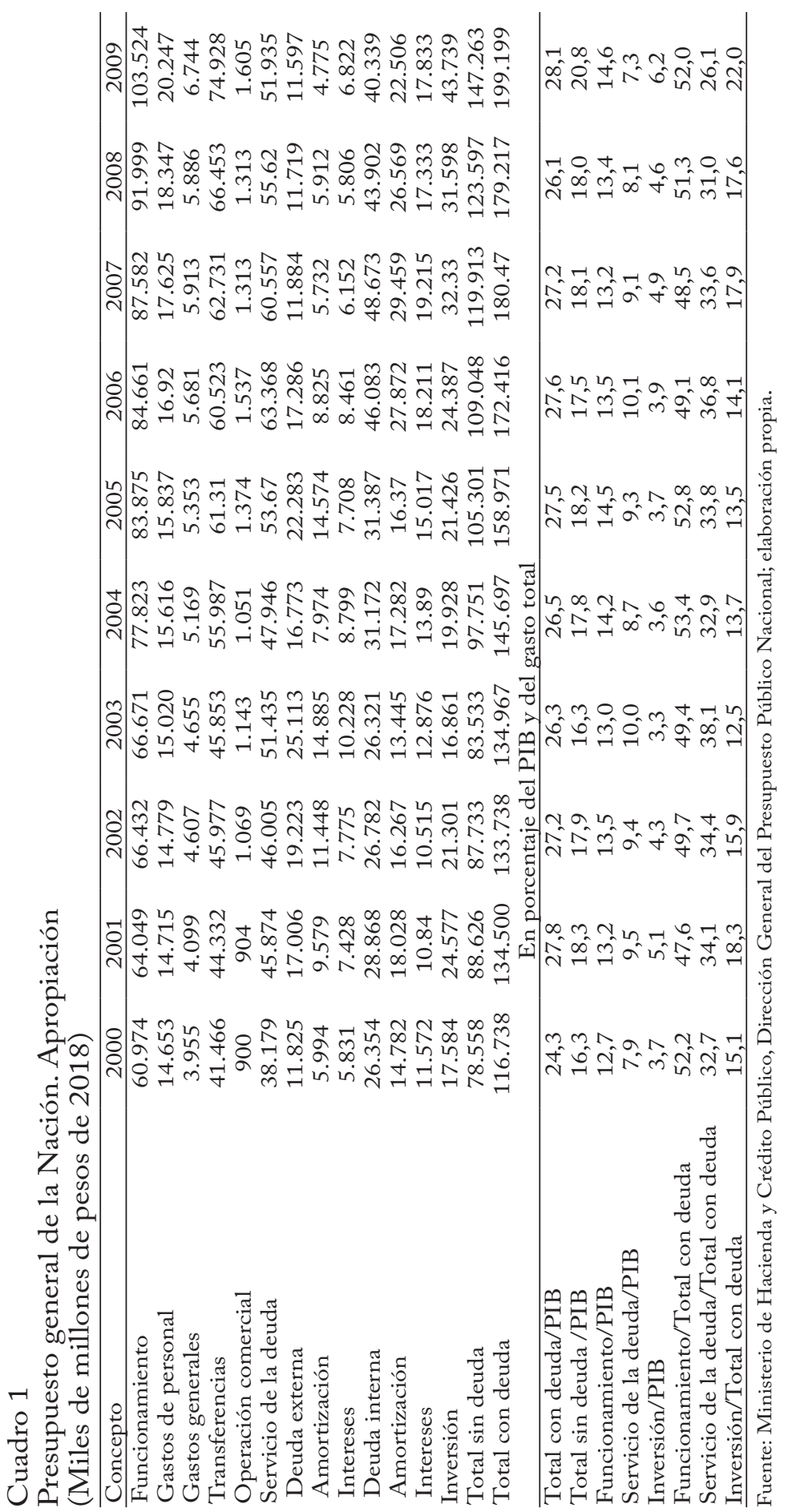

Revista de Economía Institucional, vol. 2 i, N.o 4O, Enero-junio/20i9, Pp. 29 I-326 


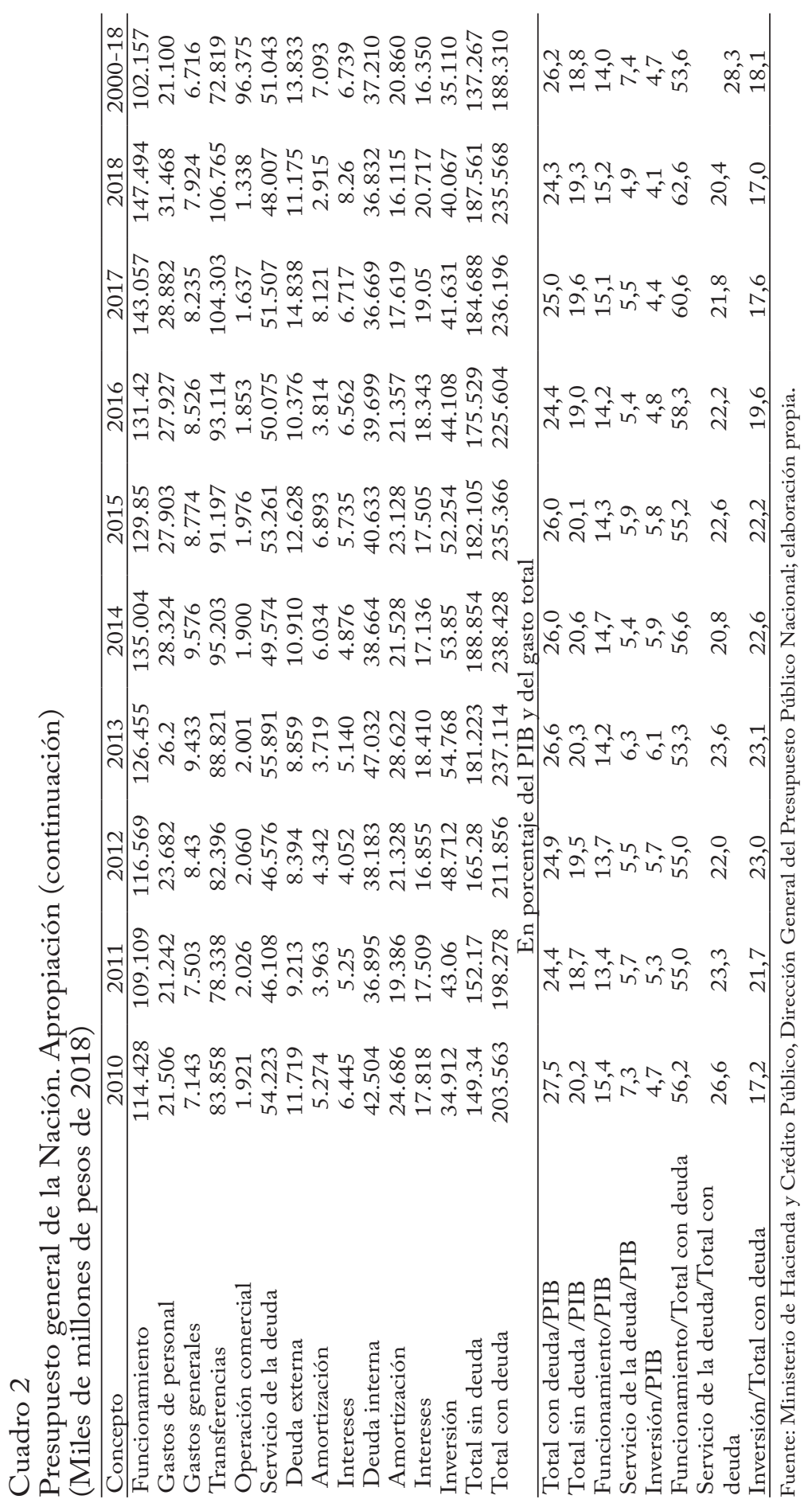

Revista de Economía Institucional, vol. 2 I, N. ${ }^{\circ}$ 40, Enero-junio/2oig, Pp. 29 I-326 


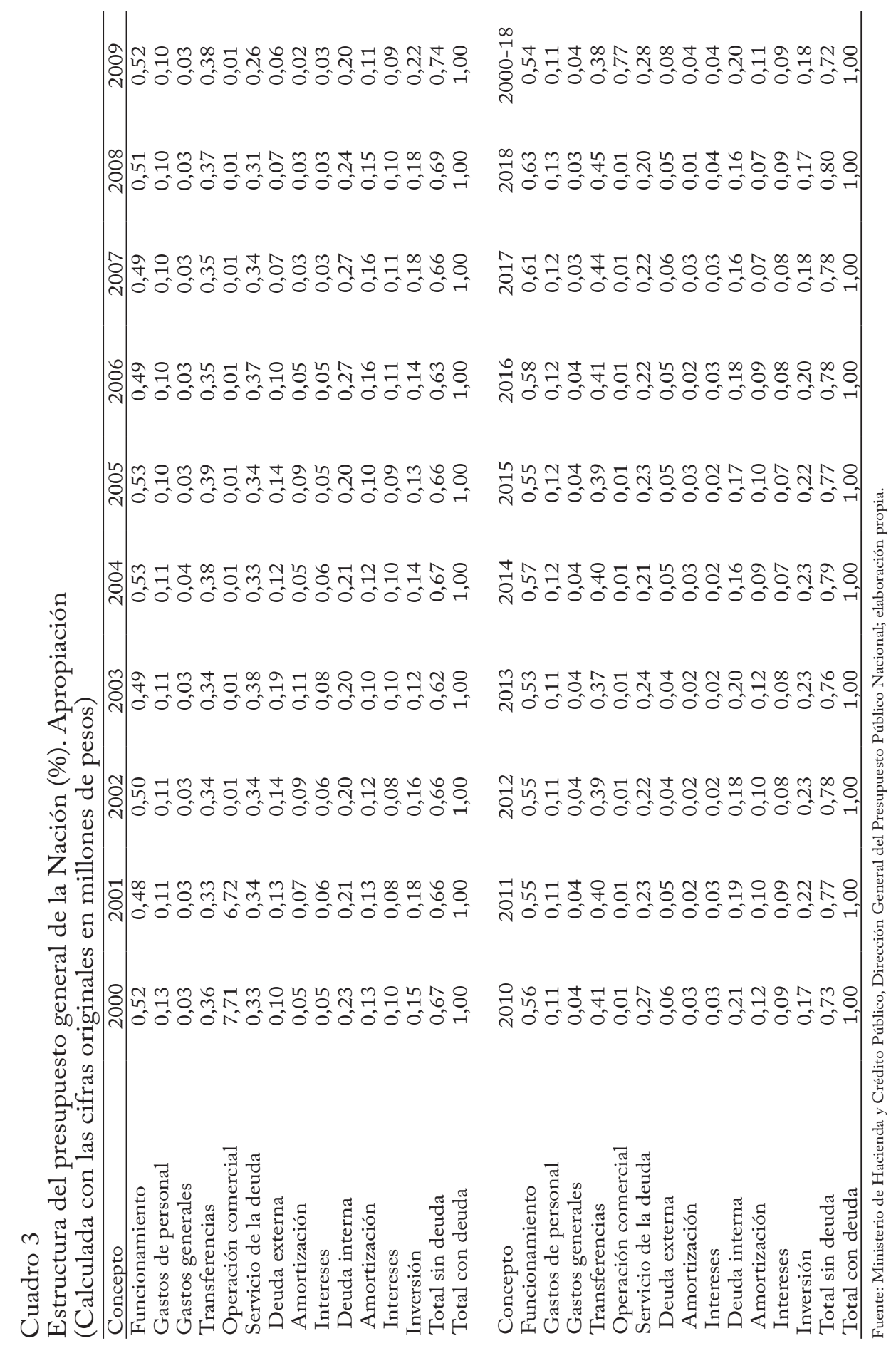

Revista de Economía Institucional, vol. 2 i, N. ${ }^{\circ}$ 40, enero-junio/20i9, Pp. 29 I-326 
Como se aprecia en el cuadro 4, entre 2000 y 2018 el gasto público colombiano aumentó el 101,8\%, a precios de 2018, es decir, a una tasa real anual promedio del $4 \%$.

Cuadro 4

Crecimiento del presupuesto general de la Nación, 2000-2018

(Cifras originales en millones de pesos de 2018)

\begin{tabular}{lccc}
\hline Concepto & $2018 / 2000$ & En 18 años & Anual \\
\hline Funcionamiento & 2,42 & 141,9 & 5,0 \\
Gastos de personal & 2,15 & 114,8 & 4,3 \\
Gastos generales & 2,00 & 100,4 & 3,9 \\
Transferencias & 2,57 & 157,5 & 5,4 \\
Operación comercial & 0,00 & $-99,9$ & $-30,4$ \\
Servicio de la deuda & 1,26 & 25,7 & 1,3 \\
Deuda externa & 0,95 & $-5,5$ & $-0,3$ \\
Amortización & 0,49 & $-51,4$ & $-3,9$ \\
Intereses & 1,42 & 41,7 & 2,0 \\
Deuda interna & 1,40 & 39,8 & 1,9 \\
Amortización & 1,09 & 9,0 & 0,5 \\
Intereses & 1,79 & 79,0 & 3,3 \\
Inversión & 2,28 & 127,9 & 4,7 \\
Total sin deuda & 2,39 & 138,8 & 5,0 \\
Total con deuda & 2,02 & 101,8 & 4,0 \\
\hline
\end{tabular}

DVS = desviación estándar; rigidez ponderada por la estructura del gasto de 2018.

Fuente: Ministerio de Hacienda y Crédito Público; elaboración propia.

Por su parte, el cuadro 3 muestra que la composición del gasto solo ha cambiado ligeramente en ese periodo de 18 años. En 2000 los gastos de funcionamiento, servicio de la deuda e inversión representaban el $52 \%$, el 33\% y el 15\% del gasto público, respectivamente; en 2018 representan el 63\%, el 20\% y el 17\%. La reducción de la participación de la deuda se tradujo en un crecimiento significativo de los gastos de funcionamiento y en mucha menor medida de la inversión.

Parece claro que la diferencia entre funcionamiento e inversión es poco útil desde el punto de vista de la política pública. Lo ideal sería avanzar hacia el presupuesto por programas, que tiene varias ventajas: 1) articula las diversas modalidades de gasto alrededor de los proyectos que se consideran relevantes; 2 ) integra los presupuestos nacional y local; 3) soluciona el problema generado por las vigencias futuras ya que el presupuesto se mantiene hasta que se concluya el programa, y 4) evita los traslapes de la actual clasificación sectorial que no consulta las necesidades de los programas.

El presupuesto también se presenta según su distribución sectorial. E1 cuadro 5 muestra la estructura de la ejecución presupuestal entre 2004 y 2017. Cabe destacar que el rubro más importante es el servicio de la deuda, que promedió el $26,7 \%$ del total. El segundo 


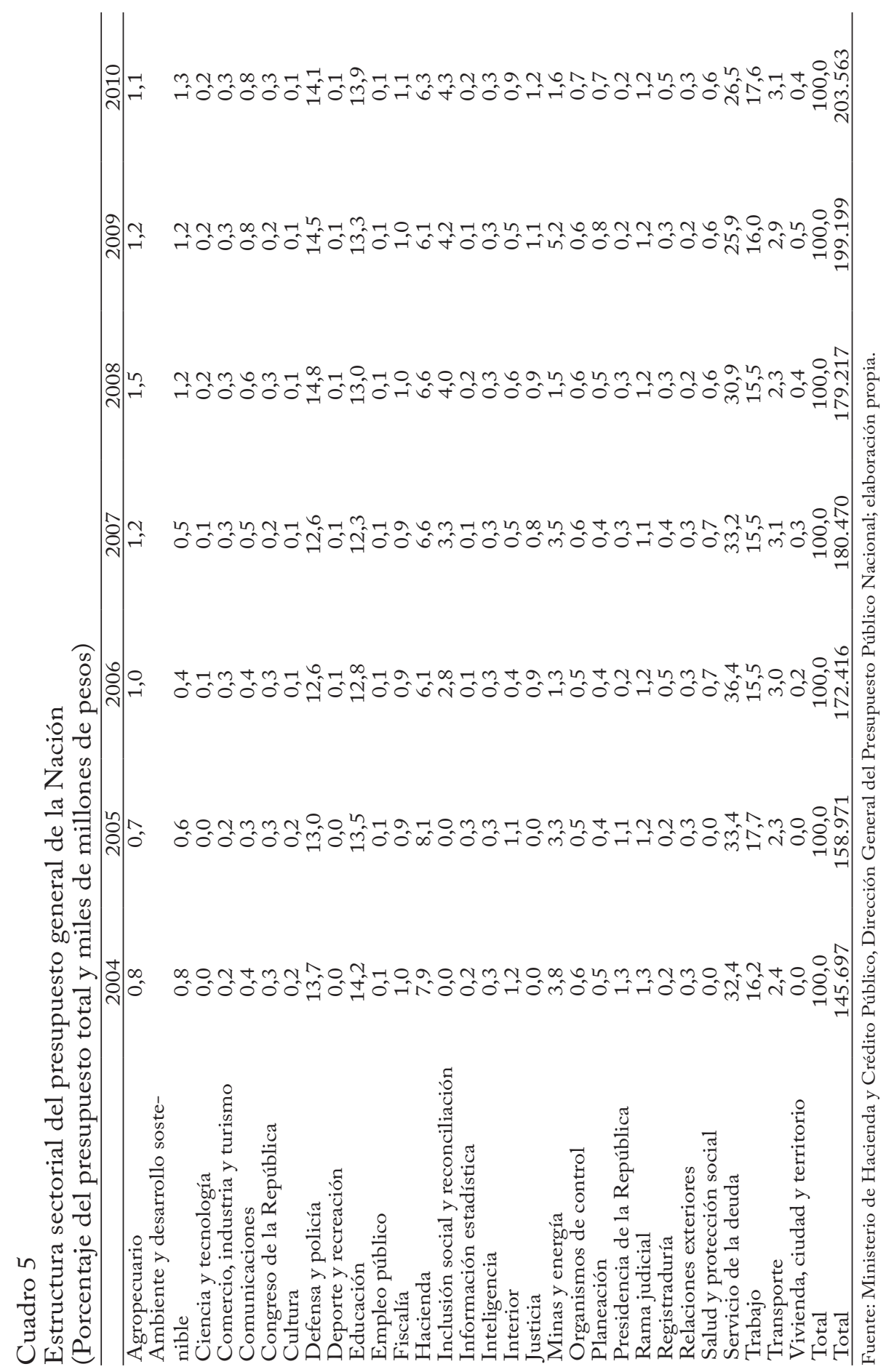

Revista de Economía Institucional, vol. 2 i, N.o 4O, Enero-junio/20i9, Pp. 29 I-326 ISSN OI 24-5996/E-ISSN 2346-2450 


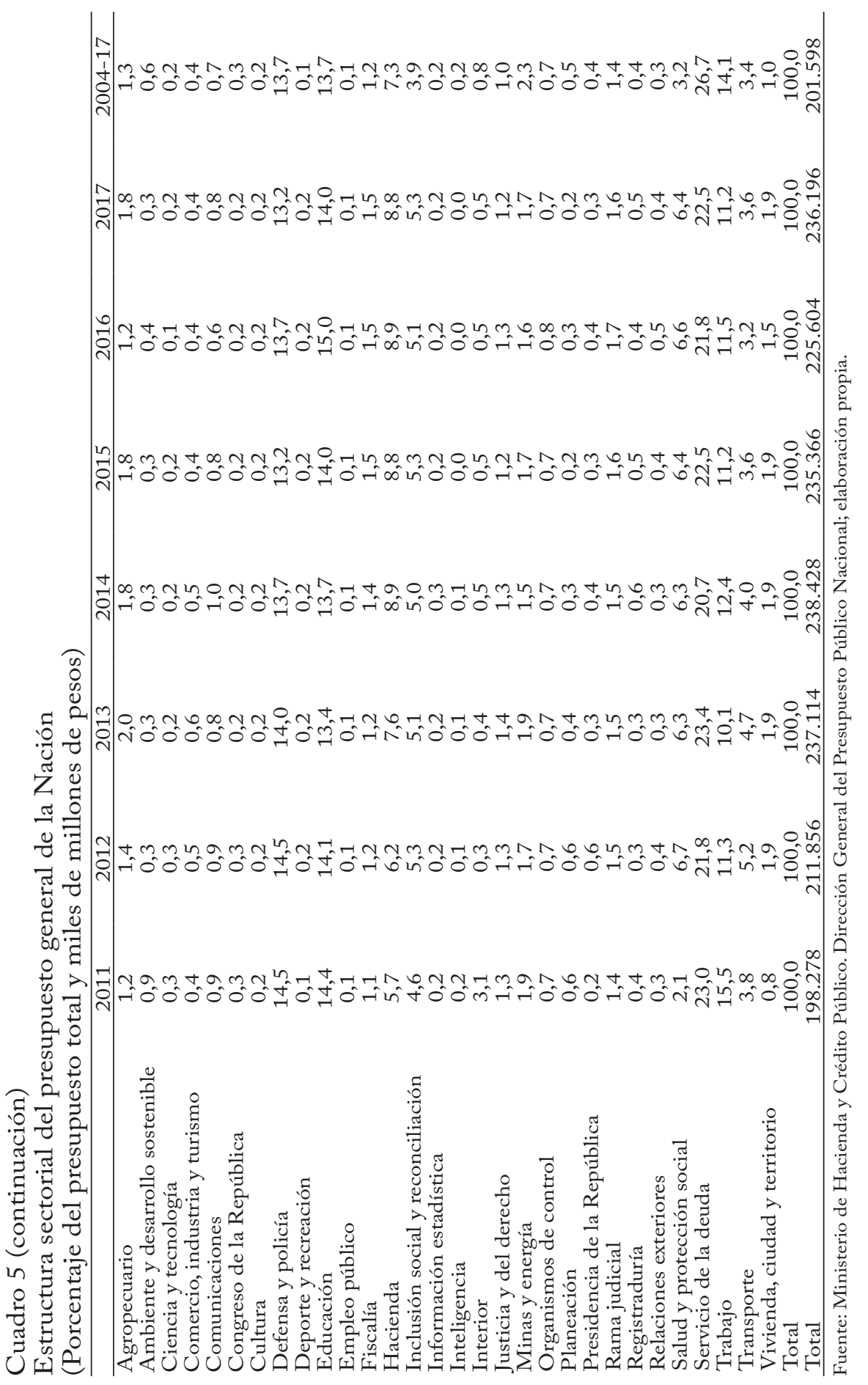

Revista de Economía Institucional, vol. 2 i, N.o 4O, Enero-junio/20i9, Pp. 29 I-326 
más importante es trabajo, que promedió el 14,1\% e incluye entidades adscritas y vinculadas como el Sena, organizaciones solidarias, Servicio Público de Empleo, Colombia Mayor, Superintendencia de Subsidio Familiar y Colpensiones.

Los dos rubros siguientes más importantes, muy superiores al resto, son educación, y defensa y policía, que entre 2004 y 2017 representaron en promedio el 13,7\% del presupuesto total. Otros sectores importantes recibieron una baja asignación promedio: transportes, 3,4\%; agropecuario, $1,3 \%$, y ciencia y tecnología, $0,2 \%$. Esa baja asignación explica la insuficiencia de carreteras -que se ha intentado paliar con alianzas público-privadas-, de canales de riego y drenaje, de bocatomas y pequeñas represas, fundamentales para el desarrollo agropecuario del país, y del apoyo a la innovación y al emprendimiento nacional.

Una comparación internacional del presupuesto colombiano permite relativizar sus dimensiones. Según el Ministerio de Hacienda y Crédito Público, para una muestra de países latinoamericanos, en 2016, el gasto colombiano equivalía al 18,9\% del PIB, apenas superior al de Perú (17,2\%), muy inferior al de Brasil (30,3\% en 2015), Argentina (24,5\%), Chile (23,6\%) y México (20,6\%), e inferior al promedio latinoamericano $(22,5 \%)$.

Es notorio que gran parte del gasto público se concentra en defensa y policía, uno de los mayores del mundo. Según el Banco Mundial, en 2016 el gasto militar, que excluye el gasto en policía, representaba en Colombia el 3,4\% del PIB, ocupando el séptimo puesto entre 136 países. En la región, en ese mismo año el gasto militar representaba el 1,3\% en Perú, el 2,2\% en Ecuador, el 1,43\% en Venezuela ${ }^{2}$ y el 1,31\% en Brasil. Es de esperar que los Acuerdos de Paz logrados permitan reducir progresivamente esa preferencia.

\section{LOS GASTOS EN EDUCACIÓN, SALUD, VIVIENDA Y SUBSIDIOS}

Según el DNP, en 2015 Colombia asignó 71,7 billones de pesos como partidas de gasto social. El sector educación recibió cerca del 31\%, salud el 21\%, pensiones el 26\%, y servicios públicos el 5,2\%. Aunque esa suma incluye subsidios, la mayoría de los gastos no lo son ${ }^{3}$.

2 E1 dato de Venezuela es de 2013; el Banco Mundial no da información más reciente.

${ }^{3}$ La nota del DNP califica todo este gasto social como subsidios: "transferencias de recursos públicos que le otorgan un beneficio económico a una persona natural o jurídica" [https://www.dnp.gov.co/Paginas/Colombiadestin\%C3\%B3-\$72-billones-a-subsidios-en-2015.aspx].

Revista de Economía Institucional, vol. 2 i, N. ${ }^{\circ}$ 4O, enero-junio/20i9, Pp. 29 I-326 ISSN OI 24-5996/E-ISSN 2346-2450 
En todo caso, es difícil saber cuánto gasta el Estado en educación, salud o seguridad, en todos sus niveles, con independencia de lo que ejecuta cada entidad. Esta es una de las razones por las cuales es conveniente avanzar hacia el presupuesto por programas. Y los programas y proyectos se podrían agrupar de tres maneras. Primero, por sectores socio-económicos; en segundo lugar, de acuerdo a los rubros generales del gasto: remuneraciones, bienes y servicios, transferencias, interés de la deuda e inversión pública, y, en tercer lugar, de acuerdo a la composición administrativa del Estado: ministerios, departamentos y municipios.

\section{EDUCACIÓN}

De acuerdo con las estadísticas de la OCDE (2017a), Colombia gasta menos por estudiante de primaria que México, Argentina, Brasil y Costa Rica, y menos que todos los miembros de la OCDE. Mientras que Colombia invierte 2.490 dólares a paridad de poder de compra (PPC) por estudiante de primaria, el promedio de la OCDE es de 8.733 dólares. En educación secundaria y media el gasto colombiano es de 3.060 dólares por estudiante, mientras que el promedio de la OCDE es de 10.106 dólares.

Dada la correlación positiva entre el gasto educativo y el desempeño académico, no sorprende entonces que Colombia obtenga puntajes muy bajos en las pruebas PISA, inferiores a la media de los países de la OCDE; en 2016, Colombia ocupó el puesto 57 en ciencias, el 54 en comprensión lectora y el 61 en matemáticas, entre 70 países ( $E l$ Periódico de Catalunya, 2016).

En términos de recursos por estudiante por nivel, la asignación para educación universitaria es mayor que para preescolar, primaria o secundaria. Esto es problemático, pues la literatura económica ha demostrado que el retorno más alto de la asignación en educación se obtiene cuando mejora la educación temprana: un buen profesor de preescolar contribuye mucho más a aumentar los futuros ingresos de un estudiante que un buen profesor universitario. Además, el acceso a la educación superior depende, en gran parte, de la calidad de la primaria y la secundaria.

Esto no significa que hay que reducir el presupuesto de las universidades para aumentar el de los otros niveles educativos. Por el contrario, si se quisiera gastar por estudiante el promedio de la OCDE, el gasto en primaria se debería aumentar en un 350\%, en bachillerato en un $330 \%$ y en educación terciaria en un $315 \%$. El presupuesto total de 
educación debería, por tanto, más que triplicarse: el gobierno tendría que destinar no 34 sino 113 billones de pesos a la educación.

En términos de cobertura, la educación es aún insuficiente. E1 $90 \%$ de los niños de 5 a 14 años va a la escuela, apenas el 55\% de los de 15 a 19 , y solo el $25 \%$ de los de 20 a 24 asiste a una institución educativa. En la OCDE las cifras correspondientes son del 97\%, el $85 \%$ y el $42 \%$, respectivamente.

Una medida importante de la calidad de la educación es el número de estudiantes por salón; cuanto menor es el número, mejor es el desempeño estudiantil. El número de estudiantes por salón de clase en primaria en Colombia es de 24 estudiantes en colegios públicos y 18 en colegios privados; en la OCDE, los colegios públicos cuentan con 21 estudiantes por salón y los privados con 20. En la secundaria colombiana hay 31 estudiantes por salón en los colegios públicos y 24 en los privados; en la OCDE son 23 y 22, respectivamente.

No sería suficiente aumentar los salarios de los maestros. Debería asegurarse que un salario más alto contribuye a la calidad de la educación. No hay duda de que se necesita atraer maestros mejores al sistema actual en jardines, colegios y universidades, y eso está correlacionado con un buen salario; pero se necesita también evaluar los rendimientos de los profesores y condicionar sus ascensos y sus mejoras salariales a resultados superiores en esas evaluaciones.

Se suele afirmar que no se debe favorecer a la educación universitaria privada por encima de la pública. En la OCDE, el 30\% de la financiación de la educación universitaria es privada, mientras que en Colombia lo es el 54\%. Es claro que la participación del sector público en la educación universitaria del país es insuficiente.

Parece haber, por tanto, distintas maneras válidas de financiar la educación terciaria. La política estatal en Colombia debería buscar la mejor calidad educativa y de investigación a costos razonables, independientemente de que el sector público o el privado desempeñen el papel más importante. Así mismo, se debe incrementar de un modo importante la inversión en equipamiento e infraestructura para la educación superior, y garantizar la alimentación para sus estudiantes más desfavorecidos.

La financiación pública es fundamental para garantizar el acceso equitativo a las universidades a los estudiantes de menores ingresos, ya sea mediante préstamos o becas, que deben aumentar y estar dirigidos a aquellos que tienen las mayores necesidades financieras.

Por otra parte, se debe evaluar cuidadosamente el impacto en la equidad del programa Ser Pilo Paga. Se podría examinar la distribu- 
ción de los costos entre el MEN y las universidades que reciben a los estudiantes más talentosos y que cobran matrículas muy altas. Ser Pilo Paga puede ser una buena combinación entre lo público y lo privado si se cumplen dos condiciones: i) el gobierno financia a la universidad de acuerdo con un valor que no depende de cada universidad sino del análisis de una estructura de costos razonable; y, ii) el pilo que en su vida laboral tenga ingresos suficientes para ser contribuyente, debe pagar una sobretasa especial sobre el impuesto a la renta para financiar la educación pública.

\section{SALUD}

Según la OCDE, el gobierno colombiano gasta el 5,4\% del PIB en salud y los particulares el 1,8\%; en la OCDE gastan el 6,5\% y el 2,5\%, respectivamente. En términos de gasto total en salud por persona, el gasto en funcionamiento en Colombia (excluyendo gastos de inversión) es bastante bajo: 964 dólares PPC por persona al año, de los cuales 724 provienen del gobierno y 240 son privados. Los países de la OCDE gastan mucho más en salud: 4.003 dólares PPC en promedio; Estados Unidos gasta 9.892 dólares PPC.

E1 logro del aseguramiento en salud ha sido notorio: el 96,6\% de la población está asegurada, un porcentaje superior al de varios países de la OCDE (2017b). No obstante, la atención en salud es insuficiente e inadecuada para las necesidades de la población.

En este sentido, siempre cabe preguntarse si resulta necesario contar con empresas financieras intermediarias que se ocupen de "asegurar" a los trabajadores y de administrar los recursos. Si de identificar ciudadanos se trata, basta con considerar la cédula de ciudadanía o de extranjería de cada persona. Por otro lado, tampoco es claro por qué unas empresas financieras deben intermediar entre pacientes e IPS, generando así un costo de intermediación que consume parte de los recursos del sistema.

Cuando comenzó a funcionar el sistema, se supuso que dos terceras partes de los trabajadores contribuirían al mismo y un tercio estaría subsidiado. Al poco tiempo de aplicado el nuevo esquema, la relación se invirtió: dos terceras partes están subsidiados y una tercera parte contribuye con sus aportes a los servicios de salud. La consecuencia de ello es que el Estado se ha visto en la obligación de suplir el faltante con los impuestos generales.

Es claro que mientras las políticas públicas promuevan el desarrollo de los sectores primarios intensivos en capital, la ocupación plena con ingresos dignos será insuficiente en Colombia. De tal 
modo, el desempleo y el subempleo, es decir la informalidad, siempre serán elevados, y la cantidad de subsidiados será siempre numerosa. Parecería más sensato contar con un sistema de prestación de salud al estilo europeo o canadiense, en donde el ciudadano, por el hecho de serlo, tiene asegurado un servicio de salud suficiente y oportuno financiado con los impuestos generales.

Los incentivos del sistema de salud en Colombia están creados para que se evite el gasto excesivo; los médicos no ganan más por aplicar tratamientos supuestamente innecesarios. Pero, por otro lado, tener incentivos para ahorrar al máximo puede llevar a una atención de calidad inferior a la deseable. La métrica utilizada debe ser la salud de los pacientes y no el gasto reducido y la utilidad de las EPS. Los incentivos económicos deben alinearse para evitar la enfermedad.

Una medida de la eficiencia de un sistema de salud es el manejo preventivo de enfermedades crónicas. La prevención evita la hospitalización y reduce costos. Según la OCDE, en 2016 el número de camas de hospital por cada 1.000 habitantes en Japón era de 13,11, en Alemania de 8,06, en Francia de 6,05, en Chile de 2,12 y en Colombia de 1,68.

Otras cifras sugieren también que el sistema de salud colombiano tiene mucho por mejorar. En 2015, la esperanza de vida era de 74,2 años, inferior a los 80,6 de la OCDE. La mortalidad infantil es de 13,6 niños por cada 1.000 partos, frente a un promedio de 3,9 en la OCDE. E1 9,5\% de los niños nace con bajo peso, frente al 6,5\% en promedio en la OCDE. E1 72,1\% de los pacientes con cáncer de seno sobrevive a los cinco años, comparado con el $85 \%$ en la OCDE, y el $34,5 \%$ frente al $62,8 \%$ con cáncer de colon, el $38 \%$ contra el $61 \%$ con cáncer de recto, y el 68,9\% versus el 86,7\% con leucemia.

Por otro lado, el sistema colombiano cuenta con pocos médicos: 1,8 por 1.000 habitantes, contra 3,4 en la OCDE. Y hay muy pocas enfermeras, menos que médicos: 1,1 por 1.000 habitantes, bastante menos que la media de 9 por 1.000 en la OCDE.

Los resultados señalados obligan a pensar, por un lado, en la necesidad de incrementar el gasto público en salud en Colombia, para acercarlo al de los países de la OCDE, y por otro lado, en la necesidad de modificar con urgencia el actual sistema de salud colombiano a fin de incrementar las políticas de prevención y la eficiencia con la que se ejecuta el gasto público.

\section{VIVIENDA}

Del total del gasto social (71,7 billones de pesos en 2015), el gasto en programas de vivienda representó el 2,6\%, equivalente a cerca de 1,8 
billones de pesos. No obstante el impulso a diferentes programas de vivienda, el gasto en programas de vivienda no es significativo en el conjunto del gasto social. Entre dichos programas resaltan: Programa de Viviendas 100\% Subsidiadas, Subsidio Familiar de Vivienda, y Mi Casa Ya.

El primer programa apoya a los hogares en situación de pobreza extrema que no pueden acceder a créditos de entidades bancarias. E1 subsidio familiar de vivienda es una ayuda sin carácter devolutivo a los hogares que reciben menos de 4 salarios mínimos legales mensuales vigentes (smlmv), y se otorga a través de las cajas de compensación familiar, el Fondo Nacional de Vivienda o el Banco Agrario.

El programa Mi Casa Ya es un programa de subsidios a la tasa de interés. Tiene varias líneas en función del valor de inmueble, subsidiando durante los 7 primeros años del crédito de financiación una cantidad de puntos de la tasa de interés: si la vivienda es de menos de $70 \mathrm{smlmv}$ (VIP) se subsidian 5 puntos, si está entre $70 \mathrm{smlmv}$ y 135 smlmv (VIS) se subsidian 4 puntos. Los dos casos anteriores aplican para los hogares con ingresos inferiores a $8 \mathrm{smlmv}$. En caso de que la familia adquiera una vivienda entre $135 \mathrm{smlmv}$ y $435 \mathrm{smlmv}$, sin importar sus ingresos, se subsidian 2,5 puntos.

Cabe señalar que subsidiar las tasas de interés es una forma de validar las altas tasas de interés que hoy cobran las entidades crediticias. Esas tasas de interés son consecuencia en gran medida de una situación de competencia monopolística en los mercados de crédito colombianos y de casi cartel en los mercados de crédito de vivienda y de consumo, como demuestra el Banco de la República ${ }^{4}$.

En los programas de vivienda los municipios y departamentos invierten recursos que no se incluyen en el gasto del gobierno central. Los programas de vivienda locales están muy relacionados con los planes de ordenamiento.

\section{SUBSIDIOS A LOS MENOS FAVORECIDOS}

E1 Departamento Administrativo para la Prosperidad Social (DAPS) se encarga de los proyectos, planes y programas enfocados en la inclusión social, la atención a grupos vulnerables y su reintegración. E1 DAPS, en 2016, tuvo una asignación presupuestal de 3,4 billones

4 "Los resultados sugieren que los mercados de crédito tienen una estructura de competencia monopolística, aunque la intensidad varía según las modalidades [...] las modalidades de vivienda y consumo son las que más se acercan a una estructura monopolística o colusiva, tipo cartel" (Banco de la República, 2017, pp. 5-6). 
de pesos, de los cuales asignó el 96\% a gastos de inversión, también llamados gastos sociales, y el $4 \%$ a gastos de funcionamiento o de operación.

Las transferencias condicionadas colombianas corresponden a los programas Jóvenes en Acción, Más Familias en Acción (MFA) e Ingreso para la Prosperidad Social. Las asignaciones presupuestales respectivas de los dos programas más importantes en 2017 fueron de 126 mil millones de pesos y de 1,2 billones, el 9\% y el 90\%, respectivamente, del presupuesto de la Dirección de Transferencias Monetarias Condicionadas (Departamento de Prosperidad Social, 2016).

El programa Jóvenes en Acción está dirigido a jóvenes vulnerables de 16 a 24 años y busca promover la continuidad en su educación. Las transferencias del programa se hacen a través de una entidad bancaria. La evidencia muestra que cuando se hacen a través de la banca se gana en educación financiera, y se ataca el problema del manejo informal del dinero (Bastagli et al., 2016).

E1 programa MFA, aplicado desde 2001, similar a Prospera de México, consiste en transferencias condicionadas en salud y educación, y reconoce dinero a familias de bajos recursos si envían sus hijos al colegio y a servicios de salud. El incentivo que se da a cada familia es de unos 140.000 pesos cada dos meses. En condiciones normales, la bancarización es del 90\% de las familias beneficiarias. En 2017 cubrió a 3.350.000 familias en situación de pobreza o pobreza extrema, víctimas del desplazamiento forzado e indígenas (Departamento de Prosperidad Social, 2017). Este programa ha mostrado resultados positivos en indicadores como asistencia escolar en niños de 12 a 17 años, nutrición infantil de los niños más jóvenes -medida por la estatura y el estado de salud-, consumo de alimentos ricos en proteína, ropa para niños y calzado (Attanasio et al., 2005).

En general, se requiere una mejor coordinación del Estado nacional con los gobiernos departamentales y municipales para evitar la superposición, el despilfarro y la ineficiencia de los subsidios.

Varias son las críticas a los programas de trasferencias condicionadas. Dados los resultados, se han utilizado en campañas políticas aprovechando que sus beneficiarios son personas vulnerables, cuando realmente estos programas corresponden a un derecho de los ciudadanos y deben ser mantenidos sin interrupción ni condicionamientos por los diferentes gobiernos.

A su vez, una gran preocupación es el desincentivo al trabajo que producirían las transferencias en los miembros de las familias receptoras. De la misma manera, cuando las transferencias son dirigidas a 
conformar el capital de nuevos negocios, el dinero podría ser gastado en otros bienes diferentes a los considerados en el programa. Un estudio reciente sobre siete programas de transferencias monetarias no encuentra efecto en el comportamiento frente al trabajo ni en hombres ni en mujeres, y tampoco en el gasto de bienes tentación, como alcohol y tabaco (Banerjee, Hanna et al., 2017).

Aunque en Colombia existen estudios de impacto de dichos programas, es necesario evaluarlos comparando la asignación de sus recursos a destinos alternativos que podrían tener mayor impacto económico y social sobre las mismas poblaciones; por ejemplo, en vez de entregarles pocos recursos muy atomizados, se les podría financiar un proyecto productivo autosostenible.

\section{LA PENSIÓN COMO DERECHO: EL INGRESO BÁSICO UNIVERSAL}

En 2017, en la estructura de gastos del gobierno nacional central (GNC) se destacan las transferencias a las regiones (Sistema General de Participaciones, SGP), el 3,7\% del PIB; las pensiones, el 3,4\%5; y el servicio de la deuda pública, el 3,1\%. El gasto en pensiones es el segundo en importancia, después del SGP.

E1 tema pensional adquiere una atención de primer nivel y se presenta como el responsable del desequilibrio fiscal. No hay duda de que merece atención, pero se debe tratar con una mirada más amplia que la del gobierno y la de los fondos privados. Es necesario reflexionar sobre las pensiones a la luz del derecho de toda persona a disponer de los ingresos necesarios para tener una vida digna. Sería ideal avanzar hacia un ingreso básico universal e incondicional. Pero para ello es necesario mejorar la tributación directa con criterios de progresividad.

\section{DiAgnóstico}

En 2017 había 20,7 millones de personas afiliadas a pensiones, 6,5 millones (el 31,3\%) en el régimen de prima media (RPM) y 14,2 millones (el 68,7\%) en el régimen de ahorro individual con solidaridad (RAIS). Hay 13,4 millones de personas que no cotizan.

${ }^{5} \mathrm{E} 1$ gasto colombiano en pensiones con respecto al PIB es relativamente bajo frente al de otros países: Italia, 14\%; Francia, 13,5\%; Austria, 12,7\%; Brasil, 12\%; Portugal, 11,9\%; Hungría, 11,3\%; Bélgica, 10,3\%; Alemania, 10,2\%; España, 8,9\%; Reino Unido, 6,7\%. 
En ambos regímenes, el empleador entrega por cuenta del trabajador aportante el $12 \%$ de sus ingresos mensuales y el trabajador el $4 \%$ (más un 1\% adicional si el ingreso base de cotización es de 4 a $16 \mathrm{smlmv}$ ). En el RPM, dichos recursos van a un fondo común que lo administra, esto es, Colpensiones. En el RAIS los recursos se acumulan en cuentas individuales en función de lo que cada uno aporte.

Por el manejo de estos últimos recursos las empresas administradoras de fondos de pensiones (AFP), que administran el RAIS, cobran una tasa fija sobre lo cotizado, independientemente de los resultados de su manejo. Tal situación configura un absurdo en una economía de mercado: todo el riesgo del manejo lo asume el cotizante; si la AFP realiza un manejo exitoso, la cuenta individual aumenta, y si el manejo es equivocado, el cotizante pierde; mientras tanto, la AFP siempre recibe un monto fijo cero-riesgo. Ya es tiempo de que las tasas que cobran las AFP dependan también de sus éxitos o fracasos.

E1 RPM incluye afiliados a Colpensiones y personas vinculadas a regímenes especiales (policía, militares, magisterio, otros). En Colpensiones, de los 6,5 millones de afiliados 1,6 ya están pensionados, y en los regímenes especiales hay 497 mil. En el RAIS hay 113 mil pensionados. Es claro, entonces, que los fondos privados aún no sienten el peso de la carga pensional, y en este momento de crecimiento el ahorro supera con creces a las obligaciones.

El total de pensionados apenas es la tercera parte de quienes ya cumplieron la edad de retiro. La informalidad, la temporalidad de los trabajos y los bajos ingresos influyen en la poca cobertura del sistema pensional. La volatilidad del mercado laboral lleva a que, en promedio, los trabajadores coticen 14,3 años (741 semanas), que no son suficientes para tener el derecho a la pensión. En el RPM se requieren 1.300 semana y en el RAIS 1.150 semanas. En el RAIS, cuando la persona llega a la edad de pensión, cumple las 1.150 semanas de cotización $\mathrm{y}$ sus beneficiarios carecen de ingresos iguales o superiores al salario mínimo, puede recibir una pensión básica.

En 2017, el gasto público en pensiones en el RPM fue de 37,5 billones de pesos. Este monto se divide en dos grandes grupos. E1 mayor corresponde a los regímenes especiales, con un gasto de 24 billones de pesos, el 69\%, y el otro componente está integrado por los afiliados a Colpensiones, con un gasto de 13,5 billones, el 31\% restante. La distinción entre los regímenes especiales y Colpensiones es fundamental porque en las discusiones públicas se suele hablar como si todos los pensionados estuvieran en Colpensiones. 
Los aportes de la Nación son una parte de los ingresos de Colpensiones. En 2007 recibió aportes de las cotizaciones de sus afiliados (7,2 billones de pesos) y de quienes se trasladaron del RAIS ( 3,8 billones). E1 total de aportes diferentes a los de la Nación fue de 12,1 billones. Entre 2013 y 2017 los aportes de la Nación pasaron de 10,5 billones a 13,5 billones.

Para atender a la población más vulnerable, en julio de 2015 se crearon los beneficios económicos periódicos (Beps), administrados por Colpensiones. Los Beps son un ahorro para la vejez. A diferencia de lo que ocurre con las pensiones, se puede optar bien sea por la anualidad vitalicia o por la compra de vivienda o de algún activo. Además, los recursos de Beps se pueden utilizar para completar los requisitos de pensión. El gobierno también ha impulsado los subsidios (65.000 pesos mensuales por persona) del programa "Colombia Mayor".

\section{SUBSIDIOS Y PROYECCIONES}

Para algunos analistas, el RPM se debe ir marchitando por dos razones: porque es inequitativo y porque está agudizando la crisis fiscal. Desde el punto de vista metodológico dicha afirmación conlleva dos dificultades importantes: la primera tiene que ver con la estimación del subsidio, la segunda con las proyecciones del déficit fiscal.

La equidad del sistema depende de la manera de calcular el subsidio. El Departamento Nacional de Planeación (DNP) y el Ministerio de Hacienda afirman que el sistema es inequitativo porque las pensiones altas reciben subsidios considerables. Se presentaría así un Robin Hood a la inversa: los cotizantes pobres financiando a los ricos. De acuerdo con estas estimaciones, una pensión de más de diez salarios mínimos, que correspondería al 1\% de los pensionados, recibiría un subsidio anual de 58,6 millones de pesos; una pensión entre ocho y diez salarios mínimos recibiría un subsidio anual de 39,1 millones; una pensión entre seis y ocho salarios mínimos recibiría un subsidio anual de 30,3 millones.

E1 subsidio es la diferencia entre el costo y la tarifa (o cualquier forma de pago). Cuando el costo es mayor que la tarifa, el subsidio es positivo. Puesto que el valor del costo se conoce, y se supone igual al gasto del gobierno en pensiones, es necesario determinar el monto de la cotización y, sobre todo, su rentabilidad a lo largo del tiempo. Estos ejercicios se tienen que realizar ex post. Puesto que los pensionados del RPM no colocaron sus ahorros en el sistema financiero, es necesario simular una rentabilidad. 
Para calcular el valor de las contribuciones de los pensionados actuales, el DNP y Hacienda aplican a las contribuciones pasadas una tasa de rentabilidad del $4 \%$ real anual. Este ejercicio es hipotético porque en el RPM los ahorros no se colocan en el sistema financiero. Se ha demostrado que si se aplica una tasa del 6\% anual ya no habría subsidios y las contribuciones serían suficientes para cubrir el valor de la pensión (Farné, 2018a y 2018b). No hay ninguna razón para utilizar el $4 \%$ ya que la rentabilidad real de los fondos de pensiones en Colombia ha sido del 7,7\% anual. Por tanto, la tasa del 6\% corresponde más a la dinámica histórica que la del 4\%. Las estimaciones de Farné desvirtúan la hipótesis del Robin Hood a la inversa.

En los cálculos de Colpensiones (cuadro 6) la estructura de aportes de la Nación es progresiva porque la relación entre aportes y nómina es mayor a medida que el ingreso disminuye. En las pensiones menores, la relación es del 73\%, y en las más altas, del 32,4\%. Esta estimación también cuestiona la conclusión del Robin Hood a la inversa.

Otro tema metodológico es el de la proyección del déficit y la situación fiscal. Los fondos de pensiones minimizan la incidencia fiscal de acabar con la prima media y pasar todos los pensionados al RAIS. En vez del 4\%, la tasa que se utiliza para estimar el subsidio, estiman los ingresos futuros con rentabilidades del 7\%. Con el $4 \%$ utilizado en los cálculos ex post, esta asimetría permite insistir en el Robin Hood a la inversa, y, por otro lado, con el 7\% que se utiliza en las estimaciones ex ante se minimiza el costo fiscal.

Cuadro 6

Pensionados, nómina y usos de aportes de la Nación, 2016

(Miles de personas y miles de millones de pesos)

\begin{tabular}{lcccc}
\hline $\begin{array}{l}\text { Salarios } \\
\text { mínimos }\end{array}$ & Pensionados & Nómina & $\begin{array}{c}\text { Aportes de la } \\
\text { Nación }\end{array}$ & $\begin{array}{c}\text { Aportes/Nómina } \\
(\%)\end{array}$ \\
\hline Hasta 1 & 632.521 & $5.465,2$ & $3.987,7$ & 73,0 \\
$1-2$ & 310.389 & $3.604,3$ & $1.992,1$ & 55,3 \\
$2-3$ & 129.309 & $2.624,8$ & $1.227,9$ & 46,8 \\
$3-4$ & 61.682 & $1.763,0$ & 776,9 & 44,1 \\
$4-5$ & 34.076 & $1.273,2$ & 529,0 & 41,5 \\
$5-10$ & 56.305 & $3.114,5$ & $1.228,4$ & 39,4 \\
$10-15$ & 12.509 & $1.175,3$ & 432,6 & 36,8 \\
$15-20$ & 3.288 & 489,7 & 145,9 & 29,8 \\
$20-25$ & 576 & 97,9 & 31,7 & 32,4 \\
Totales & 1.240 .655 & $19.607,9$ & $10.352,2$ & 52,8 \\
\hline
\end{tabular}

Fuente: Colpensiones (2017).

Puesto que en el RAIS la mayoría de los trabajadores no llega a cotizar el monto necesario para obtener una pensión mínima durante su vida laboral, el gobierno deberá subsidiar el faltante. E1 80\% de los afilia- 
dos al RAIS devenga máximo 2 salarios mínimos, y con esa suma no pueden ahorrar lo suficiente para acceder a una pensión mínima. De tal modo, el déficit que se derivaría del RAIS, aun si todas las personas migraran hacia allí, podría ser mayor que el estimado para el RPM: los fondos privados subestiman sistemáticamente el desbalance que podría tener el RAIS (Calixto, 2017).

\section{EL INGRESO BÁSICO UNIVERSAL}

Tanto en el RAIS como en el RPM, el déficit causado por las pensiones continuará aumentando. Frente a esta situación es necesario hacer algunas modificaciones paramétricas que ayudan a reducir la presión fiscal, pero sabiendo que tampoco serán suficientes.

Una solución propuesta por algunos analistas (Villar y Forero, 2018a y 2018b) es establecer un sistema multipilar. El pilar 0 sería asistencial no contributivo, que equivaldría a Colombia Mayor, complementado con los subsidios al Beps. El pilar 1, el básico contributivo, de prima media, sería equivalente a un salario mínimo. E1 pilar 2, de capitalización individual obligatoria, administrada por entidades públicas o privadas, sería para todas las personas que ganan más de un salario mínimo. E1 pilar 3 correspondería a la capitalización individual voluntaria, administrado por entidades privadas o públicas. Esta estructura reduciría el RPM únicamente al pilar 1. En cualquiera de las opciones habría déficit. Por tanto, no queda otro camino que financiar el faltante con impuestos, y estos deben ser progresivos.

Dada la baja cobertura del sistema pensional es necesario abrir la discusión sobre la conveniencia de un ingreso básico universal que garantice condiciones de vida dignas para cualquier persona. Una vez que se acepta este principio, las consideraciones sobre las pensiones adquieren una connotación diferente, que se podrían resumir así: 1) Las pensiones básicas, equivalentes a un ingreso mínimo, perderían su razón de ser, ya que todas las personas, en cualquier momento de su vida, recibirían el ingreso básico. 2) Puesto que el ingreso básico se convertiría en un derecho universal, no cabe la discusión sobre el subsidio, entendido como la relación entre el valor de la cotización y el pago recibido. 3) La progresividad del sistema dependería de la decisión colectiva de aumentar, de manera progresiva, el impuesto a la riqueza y al patrimonio de las personas naturales. 4) Por su misma naturaleza, el ingreso básico se financia con la riqueza del conjunto de la sociedad, así que, desde la mirada de la equidad, es intrínsecamente progresivo. 5) La financiación del ingreso básico solo es posible mediante mecanismos distributivos. 


\section{EL SERVICIO DE LA DEUDA PÚBLICA INTERNA Y EXTERNA}

Aunque el monto del servicio de la deuda es similar al de las pensiones, en las discusiones de política económica se da mucha más importancia al tema pensional que al endeudamiento. No hay debate público sobre las modalidades de financiación de la deuda, ni sobre el tipo de bonos que el gobierno emite, y mucho menos sobre las características de los tenedores, que son muy pocos y disfrutan de altas rentabilidades.

El problema fundamental del crecimiento de la deuda pública del gobierno nacional viene dado por el déficit estructural que presenta, sin perder de vista los posibles efectos de sus otros determinantes (crecimiento de la economía, variaciones del tipo de cambio, tasa de interés de la deuda interna y externa, inflación, entre otros).

Adicionalmente, las características de la contratación de la deuda pública y su impacto sobre el presupuesto público por la vía de las amortizaciones y de los intereses dependen de las condiciones de mercado (periodo de gracias, condiciones de amortización, tasa de interés, entre otras) a las cuales se contrate, y que difieren según se trate de deuda interna o externa (cuadro 7).

Cuadro 7

Características de la deuda pública colombiana

\begin{tabular}{lcccccccc}
\hline & & $\begin{array}{c}\text { Duración } \\
\text { (Años) }\end{array}$ & & \multicolumn{3}{c}{$\begin{array}{c}\text { Vida media } \\
\text { (Años) }\end{array}$} & $\begin{array}{c}\text { Cupón promedio } \\
\text { (Tasa anual, \%) }\end{array}$ \\
\hline $\begin{array}{l}\text { Fecha } \\
\text { corte }\end{array}$ & $\begin{array}{c}\text { Deuda } \\
\text { interna }\end{array}$ & $\begin{array}{c}\text { Deuda } \\
\text { externa }\end{array}$ & $\begin{array}{c}\text { Deuda } \\
\text { total }\end{array}$ & $\begin{array}{c}\text { Deuda } \\
\text { interna }\end{array}$ & $\begin{array}{c}\text { Deuda } \\
\text { externa }\end{array}$ & $\begin{array}{c}\text { Deuda } \\
\text { total }\end{array}$ & $\begin{array}{c}\text { Deuda } \\
\text { interna } \\
\text { (COP) }\end{array}$ & $\begin{array}{c}\text { Deuda } \\
\text { externa } \\
\text { (USD) }\end{array}$ \\
\hline Dic-02 & 2,27 & 3,93 & 3,08 & 3,97 & 6,32 & 5,13 & 14,03 & 8,75 \\
Dic-05 & 2,60 & 4,70 & 3,34 & 3,82 & 7,84 & 5,23 & 11,42 & 7,39 \\
Dic-10 & 3,77 & 5,79 & 4,36 & 4,73 & 10,56 & 6,43 & 8,38 & 5,42 \\
Dic-15 & 4,74 & 5,89 & 5,18 & 5,91 & 12,50 & 8,41 & 8,96 & 5,39 \\
Dic-16 & 4,98 & 5,28 & 5,09 & 6,16 & 11,91 & 8,20 & 8,75 & 5,34 \\
Dic-17 & 5,05 & 5,66 & 5,26 & 6,17 & 11,94 & 8,17 & 8,00 & 5,11 \\
Ene-18 & 5,01 & 5,40 & 5,14 & 6,21 & 11,88 & 8,11 & 7,85 & 5,40 \\
Feb-18 & 4,97 & 5,31 & 5,08 & 6,18 & 11,81 & 8,04 & 7,74 & 5,51 \\
Mar-18 & 5,00 & 5,22 & 5,07 & 6,21 & 11,84 & 8,06 & 7,66 & 5,82 \\
\hline
\end{tabular}

Fuente: Minhacienda.

E1 servicio de la deuda representa en 2018 cerca del 20\% del presupuesto general de la Nación, una cuarta parte le corresponde a la deuda externa y las restantes tres cuartas partes a la deuda interna. En los últimos años se optó por sustituir deuda externa por interna debido a la evolución de las condiciones de mercado, al boom de los precios de los hidrocarburos y a la variación que sufrió el tipo de cambio. La reducción del monto de los intereses de la deuda externa 
se explica por las bajas tasas de interés del mercado internacional y por la revaluación del peso. No obstante, preocupa que el saldo de la deuda del Gobierno Central Nacional con respecto al PIB haya aumentado del 38,6\% en 2010 al 46,6\% en 2017.

\section{LA INVERSIÓN PÚBLICA COMO FORMACIÓN BRUTA DE CAPITAL: TAREA POR MEJORAR}

El acervo de capital refleja la capacidad instalada empleada en la producción de bienes y servicios. No todos los países tienen las mismas necesidades de capital: cuanto mayores sean las deficiencias de un país en infraestructura, mayor inversión debe realizar, es decir, mayor formación bruta de capital fijo (FBKF), tanto privada como pública.

Desafortunadamente, los países con mayor déficit en stock de capital son los que, usualmente, tienen menos disponibilidad y peores condiciones de financiamiento de la inversión. Eso implica que cada vez sean menos competitivos.

Colombia está rezagada en la formación bruta de capital. De acuerdo con cifras del Banco Mundial, entre 1984 y 2017 tuvo un promedio de formación bruta de capital del 20,8\%, entre pública y privada, ocupando el puesto 115, por debajo de otros países de la región como Perú, Venezuela, Chile, Ecuador, Jamaica y Panamá. Cabe destacar que en los últimos doce años la FBKF colombiana ha sido mayor que el promedio de los últimos 34 años. Pero no es suficiente. Así mismo, aunque la tendencia es positiva, lo negativo es que con la reducción de la inversión pública, el peso relativo de la inversión privada ha aumentado, hasta llegar a ser 4-5 veces el de la inversión pública.

Una de las fuentes para la FBKF es la inversión extranjera directa (IED). En el caso colombiano no es preponderante: la mayor parte de la IED ha sido destinada a la adquisición extranjera de activos nacionales existentes, no a la creación de nuevas empresas productivas. La repatriación de utilidades limita también sus efectos: más del $70 \%$ de las utilidades de las empresas extranjeras son repatriadas y el saldo es reinvertido (Banco de la República, 2010). De tal modo, los recursos por IED son destinados en su mayor parte a financiar el déficit de la cuenta corriente de la balanza de pagos y no a jalonar el desarrollo del país (Moyano y Gil, 2015).

Según la CEPAL, la FBKF a cargo del Estado en Colombia, a principios de la década de 2010, representaba el 3,7\% del PIB 
(Manuelito y Jiménez, 2013); en 2018, como se indicó, el 1,7\% corresponderá a inversión del gobierno central. Panamá es el país de la región con la mayor inversión pública como porcentaje del PIB $(4,8 \%$, puesto 40 a nivel mundial), seguida de Chile (4,6\%), Uruguay (4,5\%) y Trinidad y Tobago (4,5\%). Los otros países con un nivel ligeramente menor son E1 Salvador (4,3\%), México (4,2\%), Guatemala (4,2\%), Costa Rica (4,1\%) y Brasil (4\%).

Así, América Latina y Colombia en particular tienen un nivel de inversión pública muy bajo. La consecuencia es que están muy atrasadas en infraestructura, con respecto a otras regiones. Según el Índice General de Competitividad del Foro Económico Mundial 2017-2018, en calidad de infraestructura Colombia ocupaba el puesto 87 entre 137 países, por debajo de Chile, Costa Rica, Panamá, México, Perú, Uruguay, Brasil, Guatemala y Argentina.

Desde hace algunos años, y con el fin atender la construcción de infraestructura y otras demandas sociales impostergables, se optó por promover y desarrollar alianzas público-privadas (APP). Para atraer al sector privado se aumentó y garantizó la rentabilidad de la inversión correspondiente, con cargo a sus usuarios directos y al Estado.

Mediante estas alianzas el sector privado recibe una concesión y el derecho a cobrar peajes o tarifas. Así, el reducido nivel de inversión del gobierno central se supone compensado, esperándose una solución a la notoria escasez de infraestructura a través de un cada vez mayor número de APP. Cabe señalar que en Colombia los peajes son muy altos en comparación con otros países, como México, Ecuador, Estados Unidos y algunas naciones europeas.

De manera general, en Colombia, por cada 100 pesos de ingresos se gastan 15 pesos en costos logísticos, lo cual se traduce en una baja capacidad competitiva frente a otras economías: los costos logísticos en el país no solo son un 14,7\% mayores que el promedio de América Latina, sino que son un 6\% mayores que en los países de la OCDE (Higuera, 2017).

Hay cinco reparos adicionales a estas APP:

1. Si el sector privado se dedica a invertir en carreteras o aeropuertos que debería construir el Estado, ¿con que recursos los privados construirán las fábricas que el crecimiento económico requiere?;

2. Como el sector privado demanda una rentabilidad mínima y el Estado la garantiza, este termina asumiendo todo el riesgo de la inversión;

3. Entre la rentabilidad social del proyecto y la rentabilidad privada termina primando esta última; 
4. Los proyectos siempre serán mucho más caros que los construidos por el sector público directamente (lo que explica los peajes y los costos logísticos más elevados), y

5. En muchos casos, en el colmo del absurdo, el financiamiento de la obra corre por cuenta de una empresa financiera del Estado, que es lo que precisamente la APP debería evitar: el financiamiento debería realizarse con fondos propios de la concesionaria o con recursos de otras fuentes.

Lo que Colombia requiere es aumentar de manera notable la tasa de inversión, privada y pública. Sin embargo, no parece existir la voluntad política para lograr altas tasas de inversión -y, por tanto, de ahorro doméstico- similares a las asiáticas, del 40\% al 50\% del PIB por varias décadas. Para aumentar la inversión privada debería aumentar la competitividad de las empresas (sus utilidades son la principal fuente de ahorro de la economía).

Y para generar ahorro público y posibilitar una mayor inversión pública en infraestructura debería aumentar el recaudo tributario, en particular con impuestos elevados a los patrimonios personales y a los dividendos para evitar que los recursos empresariales se destinen al consumo de sus propietarios.

\section{INSUFICIENCIA E INEFICIENCIA DEL GASTO PÚBLICO}

Como se señaló, los niveles de gasto público en Colombia son insuficientes para cumplir el mandato constitucional de una provisión adecuada de bienes y servicios públicos e infraestructura, y son bajos como proporción del PIB frente a los de los países de la OCDE y otros países latinoamericanos. Tampoco cumplen los requisitos de una gestión eficiente y eficaz. Además, mantienen una rigidez que hace difícil reprogramar el gasto de acuerdo con las necesidades sociales.

\section{CAUSAS DE LA INSUFICIENCIA}

La principal razón del bajo gasto público es, como se señaló, el insuficiente recaudo tributario, muy inferior a los estándares de los países desarrollados y del promedio de la OCDE.

A su vez, una parte significativa de los recursos se pierde en la corupción en contratos de obras públicas, cuya magnitud es muy difícil de establecer pues solo se conocen los actos que se ventilan en público. Otra parte se pierde en pagar favores políticos con la contratación de personal, lo cual refuerza el clientelismo. 
La insuficiencia del gasto es más grave si a los mandatos constitucionales se añade la financiación del Acuerdo de Paz firmado entre el Estado y las FARC. E1 monto estimado por el gobierno es de 140 billones de pesos para el periodo 2017-2031, a los que habría que sumar más de 224 billones para el componente rural estimado por la Misión para la Transformación del Campo Colombiano, y 35 billones para cubrir la ley de víctimas y restitución de tierras (Ley 1448 de 2011) de acuerdo con la Comisión de Seguimiento y Monitoreo.

\section{DiFicUlTADES EN LA GESTIÓN}

El gasto es poco eficiente: se gasta mucho, y como contrapartida se obtiene poco y con mucho retraso. Esto, en gran parte, tiene que ver con la atomización de la inversión pública, las modalidades de contratación y la selección de los ejecutores responsables del proyecto: en las licitaciones es frecuente que se otorgue la buena pro a la empresa que oferte el menor monto. Pero poco a poco se va descubriendo que dicho monto es irreal, lo que implica retrasos de los proyectos y adiciones presupuestales que también toman mucho tiempo. En otras ocasiones, particularmente en construcción de carreteras, las obras se retrasan porque las expropiaciones o la compra de los predios son postergadas debido a la acción de los propietarios en busca de un mayor valor comercial.

El gasto es poco transparente: la ciudadanía no se entera de cuánto se gasta en programas y proyectos ni cómo se distribuye en ellos; las cifras estadísticas son dispersas y difíciles de obtener, incluso para los analistas especializados.

$\mathrm{E} 1$ gasto no es verificable en su avance en términos monetarios y físicos, ni auditable en todo momento: con muy poca frecuencia se realiza un seguimiento físico del gasto, y las auditorías son solo contables y a posteriori. En ese sentido, la manera como se asigna y se gasta contribuye a la corrupción.

Aunque el gasto contribuye a generar equidad, combinado con los impactos tributarios es insuficiente para mejorar de manera sensible la distribución del ingreso. El caso de Bogotá y Cundinamarca lo ilustra: el balance financiero neto calculado para Bogotá y 32 municipios de Cundinamarca con la Encuesta Multipropósito 2014, equivalente al 19\% de la población del país, arroja como resultado que el Gini del ingreso corriente de los hogares es de 0,526. Con la imputación del gasto público en subsidios pasa a 0,499 , pero al hacer el mismo ejercicio con la carga tributaria el Gini es de 0,516, lo que indica que la 
redistribución está seriamente afectada por la falta de progresividad de la política tributaria (Gallego, González y Sepúlveda, 2017).

Los grandes proyectos de inversión no se seleccionan ni se priorizan de acuerdo con criterios de rentabilidad social: actualmente solo se busca su cierre financiero a precios de mercado.

\section{REGALÍAS Y ATOMIZACIÓN DEL GASTO}

Uno de los problemas de la inversión pública es su atomización, derivada de la manera en que se distribuye una de sus principales fuentes de financiamiento, las regalías que percibe el Estado colombiano por el aprovechamiento privado de sus recursos naturales.

De otro lado, por puro sentido de lógica económica, si la fuente de la regalía es un recurso "no renovable", se debería dedicar a mantener el "capital" del propietario, es decir del Estado, porque de otro modo sufriría un detrimento patrimonial.

Es claro que, a diferencia de lo que ocurre en los Estados de tradición anglosajona, los recursos de las regalías son del Estado y no de los particulares. Y que el Estado incluye el nivel nacional, los departamentos y municipios actuales y las regiones futuras consideradas en los artículos 306 y 307 de la Constitución.

Este punto, que parece elemental, fue distorsionado por la interpretación que el Congreso y los sucesivos gobiernos introdujeron en las leyes que rigen la distribución de las regalías y que empoderaron a los congresistas, gobernadores y alcaldes en sus áreas respectivas.

El resultado es conocido: en vez de grandes proyectos de impacto regional que mejoraran el capital físico o social del país, se financiaron 12.420 proyectos sin mayor trascendencia ni impacto, en lo que constituye un enorme desperdicio de recursos, como ha denunciado el Contralor General de la República. En este sentido, cabe retomar la filosofía inicial del constituyente de 1991: destinar las regalías a grandes proyectos regionales de aumento del capital económico y social del Estado.

\section{RIGIDEZ PRESUPUESTAL}

Una de las cuestiones más mencionadas en relación con el gasto público en Colombia es la de la rigidez cuando se trata de cambiar sus prioridades. Para intentar determinar el grado de rigidez del presupuesto para el periodo 2000-2018 se estimó la desviación estándar de cada partida, y se calculó un índice de rigidez directo (la inversa de la desviación estándar) y un índice ponderado, que resulta de calificar 
el índice directo por el peso relativo de cada rubro sobre el total del gasto en 2018. Valores más altos de los índices, directo y ponderado, por rubro representan menor volatilidad del gasto correspondiente (cuadro 8).

Las partidas más rígidas fueron las de intereses de la deuda externa, gastos generales e intereses de la deuda interna. Las menos rígidas fueron las de operación comercial, transferencias e inversión. Cuando se incorpora en el análisis el peso relativo de las partidas con respecto al total del gasto, las partidas más rígidas son las de intereses de la deuda interna, gastos de personal e intereses de la deuda externa. Y las menos rígidas, las de operación comercial, amortización de la deuda externa e inversión.

Cuadro 8

Rigidez del presupuesto general de la Nación

\begin{tabular}{|c|c|c|c|}
\hline Concepto & DVS 2000-2018 & Indice de rigidez & Rigidez ponderada \\
\hline Funcionamiento & 28,540 & 0,035 & 0,022 \\
\hline Gastos de personal & 5,778 & 0,173 & 0,023 \\
\hline Gastos generales & 1,832 & 0,546 & 0,018 \\
\hline Transferencias & 20,884 & 0,048 & 0,022 \\
\hline Operación comercial & 283,900 & 0,004 & 0,000 \\
\hline Servicio de la deuda & 5,743 & 0,174 & 0,035 \\
\hline Deuda externa & 4,630 & 0,216 & 0,010 \\
\hline Amortización & 3,479 & 0,287 & 0,004 \\
\hline Intereses & 1,542 & 0,648 & 0,023 \\
\hline Deuda interna & 7,055 & 0,142 & 0,022 \\
\hline Amortización & 4,879 & 0,205 & 0,014 \\
\hline Intereses & 3,002 & 0,333 & 0,029 \\
\hline Inversión & 12,903 & 0,077 & 0,013 \\
\hline Total sin deuda & 40,222 & 0,025 & 0,020 \\
\hline Total con deuda & 41,463 & 0,024 & 0,024 \\
\hline
\end{tabular}

DVS = desviación estándar; rigidez ponderada por la estructura del gasto de 2018.

Fuente: Ministerio de Hacienda y Crédito Público; elaboración propia.

La inflexibilidad presupuestal se debe ver también desde el punto de vista del manejo presupuestal en el corto y el mediano plazo. Ahí es claro que las transferencias, así como los gastos de personal, son supremamente inflexibles, y estos representan cerca del 50\% del presupuesto general de la Nación.

\section{Presupuesto ANUAL Y PLURIANUAL}

Otro tema relacionado con la rigidez del gasto público es su dimensión temporal de corto plazo. A pesar de las excepciones (reservas presupuestales, reservas de caja, pasivos exigibles y, sobre todo, vigencias futuras), cuya aplicación es engorrosa y a menudo se encuentra vinculada a criterios políticos partidistas, más que a la eficacia y la buena 
administración, la aplicación de la Constitución de 1991 (arts. 346 a 349 y 354) y del Estatuto Orgánico del Presupuesto legitiman una concepción anualizada de los flujos financieros oficiales que limita la posibilidad de asumir compromisos de gasto multianuales.

Esta gestión presupuestaria anualizada a menudo se justifica por la escasa capacidad del Estado para planear los ingresos fiscales a mediano y largo plazo, y tiene la ventaja de mantener bajo control los riesgos de sobregasto. Pero puede generar efectos negativos relacionados con la falta de continuidad en el gasto, que termina teniendo un impacto negativo en la calidad.

Esta visión anual del presupuesto no necesariamente debe ser la norma. En varios países se han adoptado, total o parcialmente, las herramientas de programación multianual del gasto público: en la Unión Europea, en la mayoría de los países europeos, en Canadá, Nueva Zelanda y países latinoamericanos como Brasil, México y Perú.

En el caso colombiano, una programación multianual del presupuesto público parece ser aconsejable, precisamente para evitar las anomalías indicadas. Esa programación debería referirse, por sobre todo, a los gastos de inversión, con lo que se eliminaría el problema de las llamadas vigencias futuras que, al plantear cada proyecto en forma independiente, no muestran los compromisos fiscales futuros totales, a diferencia de una programación multianual. Debería incluir también los gastos corrientes recurrentes, aquellos cuya variación resulta mínima: funcionamiento y pensiones; las proyecciones respectivas para los siguientes años son casi siempre las cifras del año anterior ajustadas por inflación.

Este presupuesto plurianual podría ser de 5 años para los rubros indicados y se debería adoptar por ley cada año. Por supuesto, no excluiría la aprobación de un presupuesto anual -que se debería guiar por el presupuesto plurianual para el año de vigencia- que incluiría todos los rubros y, en particular, los no incluidos en el plurianual. Así no se violarían las normas constitucionales mencionadas.

\section{LA CUESTIÓN DE LA CONTRATACIÓN}

Otro gran problema del gasto público en Colombia es el de la contratación, en particular de obras públicas.

En primer lugar, la tramitología innecesaria fomenta la corrupción en casi todos los niveles de contratación del Estado. Los abusos en la contratación directa son notorios y constituyen una violación de los principios de selección objetiva. Aunque también ocurren en concursos de mérito y licitaciones públicas, donde suele haber pliegos 
amañados y ofertas únicas debido a la inexistencia, hasta hace poco, de pliegos modelo. En este sentido, es un avance haber establecido pliegos licitatorios únicos, normados por la Ley 1882 de enero de 2018.

Por otra parte, son notorios los abusos del sector financiero para limitar los efectos de la causa ilícita y el objeto ilícito en contratos, c como ilustra el caso de Odebrecht. Una práctica tradicional es modificar el concepto de buena fe, exenta de culpa, en la contratación. La Ley 1882 de 2018 legalizaría este tipo de prácticas.

Otro aspecto es la debilidad de la interventoría, debido a una selección inadecuada de los interventores -los cuales en muchos casos están o terminan vinculados a los contratistas, lo que vicia su actividad- así como a los controles tardíos de los órganos de vigilancia. Los casos de Interbolsa, Reficar, Saludcoop, y de los carteles de producción y comercialización de muchos bienes y servicios, ilustran este aspecto.

En general, la respuesta del Estado ante los litigios en su contra es sumamente débil. A este respecto parece haber graves deficiencias en la Fiscalía, las Fuerzas Militares, el sector de comunicaciones e infraestructura en general.

Todo lo anterior es agravado por las dilaciones en las investigaciones penales, con sanciones pírricas cuando las hay, y la lentitud de las decisiones sobre las acciones populares y de cumplimiento que buscan proteger el interés público.

\section{GESTIÓN ESTATAL, GASTO PÚBLICO Y CORRUPCIÓN}

La corrupción es un fenómeno complejo que suele desbordar la capacidad de los mejores diseños normativos. No se limita a los sobornos, al usufructo indebido de bienes públicos, a la evasión de impuestos o a la manipulación de las normas y regulaciones públicas en beneficio propio de unos pocos empresarios, ni a la conducta de unos cuantos funcionarios públicos. En muchas ocasiones la corrupción es disfrazada con la legalización de ciertas prácticas corruptas y el ocultamiento de su impacto fiscal.

La contratación pública, en particular la referida a las obras de infraestructura, incluyendo las desarrolladas ahora a través de las APP, es una de las áreas más expuestas y a la que mayor atención debe prestarse, no solo a nivel nacional sino también regional y local.

Existen factores sistémicos que favorecen el desarrollo de la corrupción, tales como la calidad de la gobernanza o el diseño institucional (p. ej., la fragmentación del proceso de toma de decisiones de las entidades públicas o la calidad de los procesos democráticos de los partidos políticos). Pero también existen barreras más profundas 
de carácter cultural: muchos ciudadanos no son conscientes de los costos de la corrupción, aunque los pagan a manera de "impuesto" sin recibir nada a cambio. Tampoco están en condiciones de medir los daños que causa a la economía del país y hasta ignoran la existencia de los instrumentos legales e institucionales para enfrentarla.

Los escándalos agitados por los medios de comunicación pueden atraer temporalmente la atención de la opinión pública que reclama resultados rápidos contra la corrupción, pero no son suficientes para impulsar la adopción de políticas públicas con posibilidades de éxito duradero. En primer lugar, no todos los actos corruptos llegan a ser públicos, en segundo lugar, muchas veces la información que se difunde es manipulada con fines distintos a la promoción de la limpieza, la moralidad y la legalidad públicas.

Algunas reformas institucionales y legales pueden ayudar, pero el éxito de las políticas públicas depende de la participación activa de la sociedad civil en la labor de prevención y disuasión, la más efectiva en la práctica para impedir la pérdida o el desvío de dineros públicos.

Las instituciones académicas pueden y deben asumir un papel clave como dinamizadoras de la sociedad civil local, hasta ahora apática respecto de un problema endémico que requiere de tratamiento inmediato. Las instituciones académicas pueden realizar un aporte sustancial en los procesos de diseño de las políticas públicas, y en el seguimiento y evaluación de su implementación a través de sus observatorios de política pública y de sus actividades de investigación y publicación que mantienen el tema como prioridad de la agenda de reformas y lo visibilizan de manera continuada y objetiva.

\section{LEGALIDAD Y CORRUPCIÓN}

La corrupción se manifiesta también en los esfuerzos por legalizar prácticas corruptas para eludir sus consecuencias administrativas o penales. Por ejemplo, hace poco tiempo, un par de artículos incluidos en un proyecto de ley ( 285 de 2017 de la Cámara de Representantes) eliminaban las consecuencias legales de actos dolosos o culposos, como sobornos para obtener licitaciones, o negligencias sancionadas por la ley, en muchos casos penalizadas con la extinción de dominio. E1 proyecto fue aprobado y convertido en la Ley 1882 de 2018.

Aunque esto fue denunciado por el Contralor General de la República y en el Senado, no se logró impedir su aprobación. Otros órganos de control ya se habían pronunciado positivamente sobre un aspecto del proyecto de ley (los pliegos tipo, objetados por la Federación Nacional de Departamentos) pero no sobre el tema en cuestión. 
Los aspectos objetables de la Ley 1882 se encuentran en su artículo 20 , que se refiere a los contratos de asociación público-privada, suscritos o por suscribir, cuando una autoridad judicial declarara la nulidad absoluta del contrato estatal, o una autoridad judicial, administrativa o la entidad estatal contratante ordenaran su terminación con fundamento en una causal de nulidad absoluta, es decir, cuando el contrato corresponde, da origen o es consecuencia de un hecho delictivo; por ejemplo, un soborno para obtener una licitación o una concesión.

Al considerar los contratos suscritos y por suscribir, los efectos de la Ley son retroactivos, incluso para "la liquidación de los contratos de concesión de infraestructura de transporte celebrados con anterioridad a la vigencia de la Ley 1508 de 2012”.

Cambiar las reglas de juego con carácter retroactivo no es lo único cuestionable. Además, la norma garantiza a los financiadores del acto doloso o culposo la recuperación actualizada de su inversión a costa de la entidad estatal, así correspondan a un acto nulo por dolo. Más aún, según la Ley, dicha devolución puede ser cubierta con recursos del presupuesto nacional. Así, al responsable de un acto doloso se le restituye el valor de la inversión y, eventualmente, solo se le impondría una multa irrisoria.

Es absurdo legalizar lo ilegal. Y es deber de la Fiscalía, del Gobierno y del Congreso vigilar la integridad legislativa de proyectos que al convertirse en leyes terminan deteriorando la moral social, infringiendo la Constitución y perjudicando las finanzas públicas, y más aún si se aplican en forma retroactiva.

\section{¿SOLUCIONES?}

Algunas políticas públicas han demostrado su eficacia en varios países, cuando existe un compromiso real de las instituciones y de las personas encargadas de ejecutarlas. Puesto que no es posible abordar todos los aspectos de la corrupción al mismo tiempo, una estrategia realista es definir prioridades de corto, mediano y largo plazo en torno a las cuales se comprometan todos los poderes del Estado y el mayor número posible de actores clave $\mathrm{y}$, de ser posible, de la comunidad internacional.

Los temas y actividades prioritarios podrían incluir: 1) reformas institucionales, como la coordinación interinstitucional, la reingeniería de las entidades anticorrupción y la prevención de la corrupción en estas entidades; 2) seguimiento y evaluación de los gestores públicos y los legisladores, que deben recibir alta remuneración y estar sujetos 
a inspecciones frecuentes de sus cuentas bancarias e inversiones, así como a una rotación regular de los gestores y a máximo dos periodos la elección de los legisladores; 3) seguimiento y evaluación de la eficacia de las políticas anticorrupción, creación de observatorios anticorrupción, difusión de experiencias y cooperación internacional; 4) alianzas con actores clave de la sociedad civil y con los medios de comunicación; 5) cambio cultural, es decir, promoción de la cultura de la legalidad y rechazo de la máxima de "todo vale", sobre todo si es para lograr dinero abundante, fácil y rápido.

\section{REFERENCIAS BIBLIOGRÁFICAS}

Attanasio, O. et al. (2005). Cash transfers? Evidence from Colombia. Londres: Institute for Fiscal Studies briefing note 54.

Banerjee, A., Hanna, R. et al. (2017). Debunking the stereotype of the lazy welfare recipient: Evidence from cash transfer programs worldwide. World Bank Research Observer, 32(2), 155-184.

Banco de la República. (2017). Informe especial de estabilidad financiera, Concentración y competencia en los mercados de depósitos y crédito, [http://banrep.gov.co/es/publicaciones/informe-especial-de-concentraciony-competencia-en-los-mercados-de-deposito-y-credito-sep-2017].

Bastagli, F. et al. (2016). Cash transfers: What does the evidence say? A rigorous review of programme impact and of the role of design and implementation features. Londres: ODI.

Calixto, L. (2017). ¿Cuál es el costo fiscal de la dualidad en el sistema pensional colombiano? Tesis de magíster, Universidad Externado de Colombia, Bogotá.

Colpensiones. (2016). Protección para la vejez y gasto público. Bogotá: Colpensiones.

Departamento de Prosperidad Social. (2016). Informe de gestión 2016. Bogotá.

Departamento de Prosperidad Social. (2017). Informe de gestión. Enero-junio de 2017. Bogotá: Dirección de Transferencias Monetarias Condicionadas.

El Periódico de Catalunya. (2016). Resultados del informe PISA (por países y por comunidades), [https://www.elperiodico.com/es/graficos/educacion/ resultados-informe-pisa-2016-17670/].

Espitia, J., Ferrari, C. et al. (2017). Sobre la reforma tributaria estructural que se requiere en Colombia, reflexiones y propuestas. Revista de Economía Institucional, 19(36), 149-174.

Farné, S. (2018). Pensiones: no basta con reformar el régimen de Colpensiones. Razón Pública, abril.

Farné S. y Nieto, A. (2017). ¿A quiénes y cuánto subsidia el régimen pensional de prima media en Colombia? Bogotá: Universidad Externado de Colombia.

Gallego, A. M., González, J. I. y Sepúlveda, C. (2017). Evolución del balance financiero de los hogares bogotanos. Bogotá: Secretaría de PlaneaciónAlcaldía Mayor de Bogotá y Universidad del Rosario.

Higuera, E. (2017). Estas son las conexiones que necesita la logística colombiana. Dinero (4 de noviembre de 2017). 
Manuelito, S. y Jiménez, L. F. (2013). La inversión y el ahorro en América Latina: nuevos rasgos estilizados, requerimientos para el crecimiento y elementos de una estrategia para fortalecer su financiamiento. Santiago de Chile: Cepal.

Ministerio de Educación Nacional. (2017). Informe de gestión 2016. Bogotá: Oficinas Asesoras de Planeación y Comunicaciones.

Ministerio de Hacienda y Crédito Público. (2018). Marco Fiscal de Mediano Plazo 2018. Bogotá.

Moyano B., M. L. y Gil L., J. M. (2015). Efectos de la inversión extranjera directa sobre el crecimiento económico en Colombia: evidencia empírica 2000-2010. Apuntes del CENES, 34(59), 63-92.

OECD. (2017a). Education at a glance 2017: OECD Indicators. París: OECD.

OECD. (2017b). Health at a glance 2017: OECD Indicators. París: OECD. 